\title{
Фізична рекреація і рухова реабілітація - складові фізичної культури: медико-біологічні аспекти (огляд спеціальної літератури)
}

\author{
Удк 796.035:615.8 \\ В. А. Пастухова, В. М. Ільїн, М. М. Філіппов, \\ С. П. Краснова
}

Національний університет фізичного виховання і спорту України, Київ

\begin{abstract}
Резюме. Мета. На основі огляду спеціальної літератури вивчити сучасний стан поставленої проблеми. Методи. Аналіз сучасної науково-методичної та спеціальної літератури. Висновки. Вивчено вплив фізичної рекреації і рухової реабілітації на підвищення рівня фізичного стану людей. Розглянуто поняття, види, завдання, основні принципи рекреації та реабілітації, а також актуальність фізичної рекреації і рухової реабілітації як найважливіших компонентів фізичної культури. Висвітлено питання про специфічні принципи використання фізичних вправ у процесі фізичної рекреації і рухової реабілітації.
\end{abstract}

Ключові слова: рекреація, реабілітація, фізична культура.

Физическая рекреация и двигательная реабилитация составляющие физической культуры: медико-биологические аспекты (обзор специальной литературы)

В. А. Пастухова, В. М. Ильин, М. М. Филиппов, С. П. Краснова

Резюме. Цель. На основании обзора специальной литературы изучить современное состояние поставленной проблемы. Методы. Анализ современной научно-методической и специальной литературы. Выводы. Изучено влияние физической рекреации и двигательной реабилитации на повышение уровня физического состояния людей. Рассмотрены понятия, виды, задачи, основные принципы рекреации и реабилитации, а также актуальность физической рекреациии и двигательной реабилитации как важнейших компонентов физической культуры. Освещены вопросы о специфических принципах использования физических упражнений в процессе физической рекреации и двигательной реабилитации. Ключевые слова: рекреация, реабилитация, физическая культура.

Physical recreation and motor rehabilitation - physical culture constityents: medico-biological aspects (special literature review) V. A. Pastuhova, V. M. Ilyin, M. M. Filippov, S. P. Krasnova

Abstract. Objective. To study the current state of set problem on the basis of special literature review. Methods. Analysis of modern scientific and methodological and special literature. Conclusions. The influence of physical recreation and motor rehabilitation on increasing the level of people's physical condition was studied. Concepts, types, tasks, basic principles of recreation and rehabilitation, as well as the relevance of physical recreation and motor rehabilitation as the most important components of physical culture are considered. Questions about specific principles of using physical exercises in the process of physical recreation and motor rehabilitation are highlighted.

Keywords: recreation, rehabilitation, physical culture.

Постановка проблеми. Фізична культура як один із видів культури бере участь у формуванні фрізичних та інтелектуальних здібностей людини, оскільки її специфрікою є орієнтація на розвиток 
біологічної бази і фрізичних можливостей. Через єдність та взаємну обумовленість функціонування матеріальних і духовних начал у людині вона неминуче впливає і на інші сорери особистості, наприклад, емоційну, духовну тощо.

У процесі фрізкультурної діяльності людина перетворює свою природу, виступаючи при цьому не лише суб'єктом, а й об'єктом діяльності, а також ії результатом. Тому фрізичну культуру прийнято розглядати як діяльність і якісний рівень цієї діяльності, ії результатів зі створення фрізичної готовності людини до життя, праці, творчості.

Останнім часом значного поширення набула точка зору, за якої фрізична культура складається з чотирьох взаємопов'язаних компонентів: фрізичного виховання, спорту, фрізичної рекреації і рухової реабілітації $[4,14]$. Кожен із цих компонентів своїми специфічними засобами і методами задовольняє конкретні потреби тільки частково, проте тісно пов'язаний з усіма іншими, а їх спільною основою $\epsilon$ трактування теорії фрізичної культури, заснованої на концепціях загальної культури, що дозволяє з нових методологічних позицій розкрити зміст і сутність фрізичної рекреації [1]. Проте на сьогодні фрізична рекреація $€$ найменш вивченим видом фрізичної культури, і з цього приводу існують різні точки зору. Поняття «рекреація» включає різне смислове навантаження. У перекладі $з$ латинської rekretio означає «повертати здоров'я, сили». 3 англійської мови це слово перекладається так: відновлення сил; розвага, відпочинок; зміна. Зарубіжні автори розглядають цей термін у двох значеннях: по-перше, як «будь-яке приємне проведення часу, хобі, розвагу, забаву»; по-друге, «як результат, що виражається в розслабленні й освіженні після приємного проведення часу». В інших літературних джерелах фрізична рекреація знаходить своє вираження в таких термінах і поняттях, як «масова фрізична культура», «оздоровча фрізична культура», «виробнича гімнастика», «масовий спорт» тощо [5, 16, 22].

Отже, враховуючи досвід багатьох дослідників, можна вважати актуальним важливість фрізичної рекреації та рухової реабілітації для поліпшення стану здоров'я людини окремо та нації в цілому.

Мета роботи - розглянути медико-біологічні аспекти впливу фрізичної рекреації і рухової реабілітації на поліпшення рівня фрізичного стану людини.

Методи дослідження. Аналіз та узагальнення наукової та науково-методичної літератури.

Результати дослідження та їх обговорення. За критерієм діяльності слід виділяти два види рекреації: фрізичну, що пов'язана з виконанням фрізичних вправ або інших рухових дій, і інтелектуальну, яка передбачає певні розумові розваги. У загальному вигляді фрізичну рекреацію розуміють як діяльність, спрямовану на використання фрізичних вправ і природних сил з метою активного відпочинку, розваги, відновлення розумової та фрізичної працездатності [11]. Актуальність фрізичної рекреації як одного з найважливіших компонентів фрізичної культури зростає у зв'язку з переходом до ринкових відносин і появою конкуренції на ринку праці [5]. Це, мабуть, найдоступніший, демократичний і водночас найменш регламентований компонент фрізичної культури, для якого характерною $€$ незалежність від будь-якої програми. Хоча, звичайно, в окремих випадках для певних груп, що займаються, розробляються і реалізуються спеціальні програми, специфічні для вирішення конкретних завдань. Можна з упевненістю стверджувати, що фрізична рекреація буде розвиватися і вдосконалюватися, оскільки в умовах конкуренції загострюється вирішення проблем, пов'язаних із необхідністю збільшувати продуктивність праці, поліпшувати якість продукції, зберігати і зміцнювати здоров'я, а також підвищувати працездатність людини.

Окремими завданнями фрізичної рекреації можуть бути: задоволення різних потреб людей у руховій активності, розвага, переключення з одного виду діяльності на інший, профрілактика несприятливих впливів і відновлення тимчасово знижених або втрачених фуункцій організму. Ці потреби людей задовольняються кожним окремо і в цілому всіма видами рухової активності. Таким чином, створюються передумови для нормального фрункціонування людського організму в конкретних умовах його життєдіяльності. Фізична рекреація, спрямована переважно на вирішення оздоровчих завдань, розглядається як відносно вільна форма занять, що допускає зміну виду, характеру і змісту залежно від мотивів, інтересів і потреби тих, хто займається [7]. При цьому не можна забувати, що позитивний ефрект можна отримати лише за рахунок грамотної і вмілої ії організації, знання застосування фрізичних вправ та їх впливу на організм людини.

Характерними рисами фрізичної рекреації $є$ : наявність великої кількості її різновидів; доступність для людей різного віку; висока емоційність занять, у яких поєднуються елементи гри та змагання. Зазвичай, вона не потребує організаційно-управлінського регулювання, а самі заняття легко пристосувати до потреб і можливостей будь-якого середовища, групи людей, зовнішніх умов і суб'єктивних потреб людей, які займаються. Це передбачає велику свободу в підборі засобів і методів фрізичної рекреації, гнучкість і 
варіативність у процесі занять, а також урахування не тільки бажань, але і можливостей тих, хто займається [15].

Таким чином, фрізична рекреація - це органічна частина фрізичної культури, сукупність вільної, нерегламентованої рухової діяльності, спрямованої на забезпечення нормального фрізичного стану людини, що сприяє нормальному функціонуванню його організму в конкретних умовах життя і діяльності. Враховуючи величезне значення фрізичної рекреації у робочий і вільний час, на думку ряду авторів [6, 9], необхідно поглибити наукові дослідження іï компонентів, структуру, причини виникнення, етапи розвитку та функціонування для задоволення індивідуальних потреб. Проблема фрізичної рекреації представляє теоретичний i практичний інтерес з точки зору пошуків нових ефективних засобів, методів і форм її організації з метою задоволення потреб населення у відпочинку, відновлення сил, розваги, підтримання високої розумової і фрізичної працездатності.

У процесі трудової діяльності і після неї найважливішими орієнтирами використання фрізичних вправ є принципи, що відображають, з одного боку, закономірності фрізичного виховання людей, а 3 іншого - загальні закономірності оптимізації трудового процесу [6]. Відомо, що під принципами в теорії і практиці виховання передбачають ті найважливіші положення, які, узагальнено відображаючи фрундаментальні закономірності виховання у вигляді правил і вимог, спрямовують діяльність вихователя і виховуваних до поставленої мети. Принципи лише тоді приводять до дійсно цінних результатів, коли узгоджуються 3 об'єктивними закономірностями виховання. Їх практичне значення полягає в тому, що вони дозволяють не блукати на шляху до мети, переслідуваної у вихованні, а розкривають логіку вирішення деталізуючих її завдань, окреслюють головні правила їх реалізації [18].

Аналіз доступної літератури показав, що стосовно специфрічних принципів використання фрізичних вправ у процесі трудової діяльності і після неї в авторів немає єдиної думки. Одні автори формулюють ці принципи на основі фрізіологічних процесів, що відбуваються в організмі людини під час праці та відпочинку; інші виходять насамперед із принципів фрізичного виховання та інших спільних методичних принципів. Багато дослідників взагалі не формулюють ці специфрічні принципи, а пропонують конкретні методичні рекомендації та правила їх застосування. Слід зазначити, що при реалізації загальних принципів необхідно враховувати, що в процесі трудової діяльності та після ії̈ закінчення насамперед стоять специфічні завдання щодо зниження стомлення, відновлення працездатності та термінової підготовки людини до певного виду праці. Ступінь реалізації цих загальнометодичних принципів у процесі праці та відпочинку досить докладно висвітлено дослідниками [1, 3, 4, 7] у ряді наукових робіт.

При проведенні фрізкультурно-оздоровчих заходів як у режимі трудової діяльності, так і після неї особливо важливого значення набуває принцип доступності та індивідуалізації. Важливість і особливості цього принципу у сорері фрізичного виховання обумовлені насамперед тим, що в процесі занять фрізичними вправами серйозного навантаження зазнають рухові та інші життєво важливі функції організму. Якщо при цьому перевищується посильна міра навантажень, виникає загроза виникнення негативного ефекту і замість позитивного оздоровчого ефекту починає проявлятися негативний вплив [18]. У зв'язку з цим, програму занять фрізичними вправами необхідно будувати відповідно до можливостей працівників, враховуючи особливості віку, статі, рівень попередньої фрізичної підготовленості тощо. Повна відповідність між можливостями людини і реальними труднощами означає оптимальну міру доступності. Конкретне визначення і дотримання міри доступності фрізичних вправ $є$ однією з актуальних проблем використання фрізичної рекреації в процесі трудової діяльності та післятрудової реабілітації працюючих. За результатами численних наукових досліджень професор Ю. П. Галкін [6] сорормулював основні специфічні принципи використання фрізичної рекреації: принцип відповідності засобів, методів і форм занять; принцип контрастності; принцип хвилеподібності.

У теоретичному осмисленні та практичній реалізації першого принципу особливе місце займають наукові роботи вітчизняних фрахівців $[1,4,5]$. На сьогодні досить переконливо доведено, що ігнорування особливостей трудової діяльності та довільне застосування форм, засобів і методів занять у вигляді фрізичної рекреації в режимі робочого дня і після його закінчення може виявитися не тільки не ефективним, а навіть шкідливим у забезпеченні оптимального рівня працездатності працюючих людей.

Керуючись сучасними уявленнями про фрізіологічний вплив активного відпочинку, срахівці $[14,20]$ дають конкретні методичні рекомендації щодо організації та проведення фрізкультурно-оздоровчих і відновних заходів на багатьох підприємствах, в основу яких покладено принцип контрастності, заміни одного виду діяльності на інший. Відомо, що в різних циклах трудового процесу динаміка працездатності має фразовий характер, хвилеподібно 
змінюється. Пов'язуючи це положення з реалізацією принципу контрастності, можна прийти до висновку, що зі збільшенням трудового навантаження на організм працюючого, підвищенням його стомлюваності загальна кількість додатково виконуваних фрізичних вправ як у процесі праці, так і в період післятрудової діяльності має зменшуватися і навпаки. Експериментальна перевірка показала, що найбільш ефективним у досягненні і підтримці високого рівня профресійної працездатності працюючої людини $€$ нерівномірний, хвилеподібний розподіл обсягу виконуваних фрізичних вправ у рамках робочого дня і протягом усього робочого тижня [6]. Слід підкреслити, що цим принципом можна керуватися також при плануванні та проведенні різних фрорм фрізичної рекреації у позаробочий час.

Розробка та науково обгрунтована побудова раціональних рухових режимів з урахуванням їх вікових, статевих та індивідуальних особливостей на основі системного підходу представляють один із основних напрямів науково-дослідних робіт, які стосуються проблем неспеціальної фрізкультурної освіти працюючих людей. Але для того щоб індивідуалізувати програму фрізкультурної освіти людини, необхідно індивідуалізувати контроль за iї функціональним станом [21]. Тестування фрізичної підготовленості та фрункціонального стану має бути масовим і здійснюватися за стандартизованими методиками, що обумовлює необхідність комп'ютеризації цього процесу. Застосування обчислювальної техніки, спеціально розроблених програм, аналіз результатів із подальшою роздруківкою індивідуальних рекомендацій - реальний шлях зробити етап самостійних занять масовим.

Серед працівників різних підприємств набуває застосування рухова реабілітація у фооммах організованих і особливо самостійних занять у позаробочий час.

Реабілітація в перекладі з латинської означає «відновлення». Вона трактується як ряд профрілактичних заходів, спрямованих на відновлення порушених орункцій організму і працездатності. Найважливішим завданням реабілітації в трудовій

\section{Література}

1. Андрєєва О. Основні ознаки, функції фізичної рекреації у контексті залучення населення до рухової активності / О. Андрєєва, О. Лазарєва // Фізична культура, спорт та здоров'я нації: зб. наук. пр. Вінницького держ. пед. ун-ту ім. Михайла Коцюбинського. - 2012. - № 14. - С. 150-156.

2. Бирюков А. А. Лечебный массаж / А. А. Бирюков. - М.: Академия, 2004. $-368 \mathrm{c}$

3. Боголюбов В. М. Физические факторы в профрилактике, лечении и медицинской реабилитации / В. М. Боголюбов. - М.: Медицина, 2002 - 376 с.

4. Булатова М. М. Сучасні фізкультурно-оздоровчі технології у фізичному вихованні / М. М. Булатова, Ю. А. Усачов // Теорія і методика діяльності $€$ необхідність домагатися не тільки повного клінічного, але й функціонального відновлення (тобто досягти функцціонального рівня, наявного у працівника до захворювання або травми), що забезпечує можливість включатися в трудовий процес без негативних наслідків для здоров'я $[12,13]$.

Ґрунтуючись на вищевикладеному, дослідники $[2,17,19]$ визначають рухову реабілітацію як спеціально організований і свідомо керований процес занять фрізичними вправами, спрямований на відновлення порушених функцій і працездатності людей після перенесення захворювань, травм, фрізичних і психічних перенапружень, характерних для деяких видів і факторів трудової діяльності на сучасних підприємствах. Найчастіше рухова реабілітація проводиться в профрілакторіях, санаторіях, будинках відпочинку, госпіталях, лікарнях [10].

У трудовій практиці фрізична реабілітація передбачає лікування травм, отриманих у процесі трудової діяльності, а також відновлення фрізичного стану після перенесених травм. Тут фрізична реабілітація нерозривно пов'язана з лікувальною фрізичною культурою. Специфріка лікувальної фрізичної культури полягає у використанні основних лікувальних засобів фрізичних вправ - стимулятора життєвих фрункцій організму людини. Основним у застосуванні цього методу є свідоме й активне використання хворими фрізичних вправ у лікувальному процесі. Необхідним у процесі реабілітації $є$ раціонально і правильно організований руховий режим. Характер фрізичних вправ, дозування, поєднання навантажень і відпочинку повинні відповідати об'єктивному стану здоров'я людини. Фізичні навантаження повинні мати переважно неспецифічний характер, з обмеженням вправ, що вимагають силових напружень і виконуваних з великою інтенсивністю. Заняття не слід доводити до вираженого стомлення [12, 22].

Однак при всьому різноманітті наукових досліджень про місце фрізичної культури в житті працюючої людини слід визнати, що питання конкретного впливу фрізичної рекреації і рухової реабілітації на підвищення рівня фрізичного стану людей потребують подальшого вивчення.

\section{References}

1. Andryeyeva, O., \& Lazarieva, O. (2012). Osnovni oznaky, funktsiyi fizychnoyi rekreatsiyi u konteksti zaluchennya naselennya do rukhovoyi aktyvnosti [Main features, functions of physical recreation in the context of attracting people to motor activity]. Fizychna kul'tura, sport ta zdorov'ya natsiyi: zbirnyk naukovykh prats' Vinnyts'koho derzhavnoho pedahohichnoho universytetu imeni Mykhayla Kotsyubyns'koho - Physical culture, sports and health of the nation: a collection of scientific works of the Vinnitsa State Pedagogical University named after Mikhail Kotsyubinsky. Vinnytsya, 14, 150-156 [in Ukrainian].

2. Biryukov, A.A. (2004). Lechebnyy massazh [Massotherapy]. Moscow: Akademiya [in Russian]. 
фіз. виховання; за ред. Т. Ю. Круцевич. - К. : Олімп. л-ра, 2008. - Т. 2. C. $320-354$.

5. Выдрин В. М. Физическая рекреация - вид физической культуры / В. М. Выдрин // Культура физическая и здоровье. - 2004 . - № 2. - С. 1821.

6. Галкин Ю. П. Физическая культура работников промышленного производства / Ю. П. Галкин // Теория и практика физ. культуры. - 2000. № 9. - С. 53-56.

7. Гері Окамото. Основи фізичної реабілітації / Окамото Гері; пер. з англ. - Львів : Галицька видав. спілка, 2002. - 294 с.

8. Граевская Н. Д. К проблеме нормы и переходных состояний в спорте / Н. Д. Граевская, Г. А. Гончарова // Вестн. спорт. медицины России. - 1997. - Т. 15, № 2. - С. 84-98.

9. Епифранов В. А. Лечебная физическая культура и спортивная медицина / В. А. Епифанов. - М. : Медицина, 1999. - 304 с.

10. Журавлева А. И. Спортивная медицина и лечебная физкультура / А. И. Журавлева, Н. Д. Граевская. - М. : Медицина, 1993. - С. 103-138.

11. Зайцев В. П. Методология физической рекреации: взгляд на проблемы, опыт, рекомендации / В. П. Зайцев, С. В. Манучарян, К. Прусик и др. // Педагогіка, психологія та медико-біол. пробл. фіз. виховання і спорту: зб. наук. праць / за ред. С. С. Єрмакова. - 2013. - № 4. - С. 13-20.

12. Ибатов А. Д. Основы реабилитологии / А. Д. Ибатов, С. В. Пушкина. - М. : ГЭОТАР-Медиа, 2007. - 160 с $463 \mathrm{c}$

13. Иваничев Г. А. Мануальная медицина / Г. А. Иваничев. - 2005. -

14. Іващенко Л. Я. Фізичне виховання дорослого населення / Л. Я. Іващенко, О. Л. Благій // Теорія і методика фіз. виховання і спорту. - 2008. - С. 190-230.

15. Кручевич Т. Ю. Рекреація у фізичному вихованні різних груп населення / Т. Ю. Круцевич, Г. В. Безверхня. - К. : Олімп. л-ра, 2010. - 200 с.

16. Левицький В. В. Термінологічний апарат у галузі оздоровчої фізичної культури / В. В. Левицький // Теорія і методика фіз. виховання і спорту. - 2000. - № 2-3. - С. 93-95.

17. Майкели Л. Энциклопедия спортивной медицины / Л. Макейли, М. Дженинкс. - СПб. : Лань, 1997. - 417 с.

18. Малина Р. М. Исследование двигательной активности и физического фитнеса в различные периоды жизни / Р. М. Малина // Наука в олимп. спорте. - 2001. - № 3. - С. 16-27.

19. Матвеев Л. П. Основы общей теории спорта и система подготовки спортсменов / Л. П. Матвеев. - К. : Олимп. лит., 1999. - 316 с.

20. Учебник инструктора по лечебной физической культуре / [под ред. В. П. Правосудова]. - М. : Физкультура и спорт, 1980. - С. 357-364.

21. Ущмаров А. К. Общая физиотерапия / А. К. Ушмаров, Д. Р. Ракита, Н. А. Рондалева, В. Я. Гармаш. - Рязань, 2002. - 124 с.

22. Физическая реабилитация: учеб. для студ. высш. учеб. заведений / [под общей ред. проф. С. Н. Попова]. - [3-е изд.]. - Ростов н/Д. : Феникс, 2005. - 608 c.

\section{Спортивна медицина і фізична реабілітація, № 2, 2017}

3. Bogolyubov, V.M. (2002). Fizicheskiye faktory v profilaktike, lechenil i meditsinskoy reabilitatsii [Physical factors in the prevention, treatment and medical rehabilitation]. Moscow: Meditsina [in Russian].

4. Bulatova, M.M., \& Usachov, Yu.A. (2008). Suchasni fizkul'turnoozdorovchi tekhnolohiyi u fizychnomu vykhovanni [Modern physical culture and health technologies in physical education]. Teoriya i metodyka fizychnoho vykhovannya - Theory and methods of physical education. T.Yu. Krutsevych (Ed). (Vols. 1-2; Vol. 1). Kyiv: Olimpiys'ka literatura, p. 320-354 [in Ukrainian].

5. Vydrin, V.M. (2004). Fizicheskaya rekreatsiya - vid fizicheskoy kul'tury [Physical recreation - a kind of physical culture]. Kul'tura fizicheskaya i zdorov'ye - Culture physical and health, 2, 18-21 [in Russian].

6. Galkin, Yu.P. (2000). Fizicheskaya kul'tura rabotnikov promyshlennogo proizvodstva [Physical culture of workers in industrial production]. Teoriya praktika fizicheskoy kul'tury - Theory and practice of physical culture, 9, 53-56 [in Russian].

7. Hery, Okamoto (2002). Osnovy fizychnoyi reabilitatsiyi [Fundamentals of physical rehabilitation]. L'viv: Halyts'ka vydavnycha spilka [in Ukrainian].

8. Grayevskaya, N.D., Goncharova, G.A. (1997). K probleme normy i perekhodnykh sostoyaniy $v$ sporte [To the problem of norm and transitional states in sports]. Vestnik sportivnoy meditsiny Rossii - Bulletin of sports medicine of Russia, Vol. 15, 2, 84-98 [in Russian]

9. Yepifanov, V.A. (1999). Lechebnaya fizicheskaya kul'tura i sportivnaya meditsina [Therapeutic physical culture and sports medicine]. Moscow: Meditsina [in Russian]

10. Zhuravleva, A.I., Grayevskaya, N.D. (1993). Sportivnaya meditsina i lechebnaya fizkul'tura [Sports Medicine and Physiotherapy]. Moscow: Meditsina, p. 103-138 [in Russian].

11. Zaytsev, V.P., Manucharyan, S.V., \& Prusik, K. (2013). Metodologiya fizicheskoy rekreatsii: vzglyad na problemy, opyt, rekomendatsii [Methodology of physical recreation: a look at problems, experience, recommendations] S.S. Yermakov (Ed.). Pedahohika, psykholohiya ta medyko-biolohichni problemy fizychnoho vykhovannya i sportu: zbirnyk naukovykh prats' Pedagogy, psychology and medical-biological problems of physical education and sports: a collection of scientific works, 4, 13-20 [in Ukrainian].

12. Ibatov, A.D., Pushkina, S.V. (2007). Osnovy reabilitologii [Basics of Rehabilitation]. Moscow: GEOTAR-Media [in Russian].

13. Ivanichev, G.A. (2005). Manual'naya meditsina [Manual medicine] [in Russian].

14. Ivashchenko, L.Ya., Blahiy, O.L. (2008). Fizychne vykhovannya dorosloho naselennya [Physical education of the adult population]. In: Teoriya i metodyka fizychnoho vykhovannya i sportu - Theory and methods of physical education and sport, p. 190-230 [in Ukrainian].

15. Krutsevych, T.Yu., Bezverkhnya, H.V. (2010). Rekreatsiya u fizychnomu vykhovanni riznykh hrup naselennya [Recreation in the physical education of different groups of the population]. Kyiv: Olimpiys'ka literatura [in Ukrainian].

16. Levyts'kyy, V.V. (2000). Terminolohichnyy aparat u haluzi ozdorovchoyi fizychnoyi kul'tury [Terminology device in the field of recreational physical culture]. Teoriya i metodyka fizychnoho vykhovannya i sportu - Theory and methods of physical education and sport, 2-3, $93-95$ [in Ukrainian].

17. Maykeli, L., Dzheninks, M. (1997). Entsiklopediya sportivnoy meditsiny [Encyclopedia of Sports Medicine]. Sankt Peterburg: Lan' [in Russian].

18. Malina, R.M. (2001). Issledovaniye dvigatel'noy aktivnosti fizicheskogo fitnesa $v$ razlichnyye periody zhizni [Research of physical activity and physical fitness in different periods of life]. Nauka v olimpiyskom sporte Science in the Olympic sport, 3, 16-27 [in Russian].

19. Matveyev, L.P. (1999). Osnovy obshchey teorii sporta i sistema podgotovki sportsmenov [Fundamentals of the general theory of sports and the system of training athletes]. Kiev: Olimpiyskaya literatura [in Russian].

20. Pravosudov, V.P. (Ed.). (1980). Uchebnik instruktora po lechebnoy fizicheskoy kul'ture [Textbook of the instructor in curative physical culture]. Moscow: Fizkul'tura i sport, p. 357-364 [in Russian].

21. Ushmarov, A.K., Rakita, D.R., Rondaleva, N.A., \& Garmash, V.Ya. (2002). Obshchaya fizioterapiya [General physiotherapy]. Ryazan' [in Russian]

22. Popov, S.N. (Ed.). (2005). Fizicheskaya reabilitatsiya [Physical rehabilitation]. [3rd ed.]. Rostov na Donu: Feniks [in Russian]. 